\title{
A leverage points perspective on social networks to understand sustainability transformations: evidence from Southern Transylvania
}

\author{
David P. M. Lam ${ }^{1,2}$ (D) Berta Martín-López ${ }^{1} \cdot$ Andra I. Horcea-Milcu $^{3} \cdot$ Daniel J. Lang ${ }^{1,2}$
}

Received: 29 November 2019 / Accepted: 4 November 2020 / Published online: 2 December 2020

(c) The Author(s) 2020

\begin{abstract}
Sustainability transformations research increasingly recognizes the importance of local actors and their networks to foster fundamental societal change. Local actors have different types of relations between each other (e.g., sharing material resources, giving advice) through which they jointly intervene in different system characteristics. We conducted social network analyses of 32 non-governmental organizations (NGOs) who drive initiatives to foster sustainability in Southern Transylvania, Romania. In so doing, we applied a leverage points perspective by differentiating between relations according to the system characteristic they address, such as the parameters, feedbacks, design and intent of the system. Additionally, we tested for differences of centrality metrics (i.e., weighted degree, betweenness, eigenvector) from NGOs that conduct different actions (i.e., amplification processes) to increase the impact of their sustainability initiatives. Our results reveal several NGOs that have central positions in their networks for intervening in both shallower (i.e., parameters and feedbacks) and deeper (i.e., design and intent of a system) system characteristics. We also identified NGOs that are only central for intervening in specific system characteristics. In addition, we found that specific groups of amplification processes (i.e., amplifying within and out) are associated with the NGOs' positions in the parameters, feedbacks, and design networks. We conclude that the leverage points perspective in social network analysis has the potential to identify key actors and shed light on the attributes of local actors for intervening in shallower and deeper system characteristics to foster sustainability transformations.
\end{abstract}

Keywords Leverage points $\cdot$ Romania $\cdot$ Scaling $\cdot$ Social network analysis $\cdot$ System change $\cdot$ Transformation $\cdot$ Transition

\section{Introduction}

Handled by Julia Leventon, Leuphana University, Faculty of Sustainability, Germany.

Electronic supplementary material The online version of this article (https://doi.org/10.1007/s11625-020-00881-z) contains supplementary material, which is available to authorized users.

David P. M. Lam

lam@leuphana.de

1 Institute for Ethics and Transdisciplinary Sustainability Research, Faculty of Sustainability, Leuphana University Lüneburg, Universitätsallee 1, 21335 Lüneburg, Germany

2 Institute for Sustainable Development and Learning, Faculty of Sustainability, Leuphana University Lüneburg, Universitätsallee 1, 21335 Lüneburg, Germany

3 Hungarian Department of Biology and Ecology, Babes-Bolyai University, Str. Clinicilor 5-7, Cluj-Napoca 400006, Romania
Humanity is facing fundamental sustainability challenges, such as biodiversity loss and climate change (Barnosky et al. 2011; IPCC 2018). During the last 20 years, sustainability science has emerged as a well-established field aspiring to contribute to solving these pressing challenges (Kates et al. 2001; Komiyama and Takeuchi 2006). Within this field, the notion of transforming unsustainable human-environment systems has received increased interest and led to a sophisticated understanding of sustainability transformations (Loorbach et al. 2017; Horcea-Milcu et al. 2020; Scoones et al. 2020). Sustainability transformations refer to "fundamental changes in structural, functional, relational, and cognitive aspects of socio-technical-ecological systems that lead to new patterns of interactions and outcomes" (Patterson et al. 2017). Examples of these systems are mobility, energy, fisheries, agriculture, forestry, or water systems (Loorbach et al. 2017). 
Transformations are multiphase and multilevel processes where crisis can provide a window of opportunity for largescale change (Olsson et al. 2006; Westley et al. 2011). The multiple interconnected phases they are comprised of are: preparation, navigating the transition, and consolidation. Changes in these phases can take place on multiple levels: the micro-, meso-, and macro-level of a system (Geels 2002; Olsson et al. 2004, 2006; Moore et al. 2014; Pereira et al. 2018).

Sustainability interventions are deliberate actions from people that seek to foster desired transformative change within systems of interest (Dorninger et al. 2020). Until now, many interventions have not led to the system transformations needed to cope with urgent sustainability challenges, as in the case of food or energy systems (Dorninger et al. 2020). Prevailing interventions tend to foster incremental changes with limited potential for system-wide, transformative change (Abson et al. 2017; Dorninger et al. 2020).

Interventions can be implemented through global topdown sustainability initiatives that are often led by governmental actors (e.g., Sustainable Development Goals, Convention on Biological Diversity) and through bottomup initiatives from local actors who play a crucial role in fostering place-based transformations (Stirling 2015; Balvanera et al. 2017). Local actors, including individuals or groups of people (e.g., initiatives, projects, communities, organisations, or companies), have agency to act at a local scale and drive bottom-up initiatives as a response to environmental and social challenges (Liehr et al. 2017; Schlüter et al. 2019). Local actors and their sustainability initiatives can provide multiple and innovative ideas to address sustainability challenges and intervene in systems while representing a diversity of practices, knowledge systems, worldviews, values, and regions (Bennett et al. 2016; Lam et al. 2020a). Initiatives can focus on, for instance, sustainable production and consumption of food, energy, or water, or the conservation of biodiversity and cultural heritage (Bennett et al. 2016). Sustainability initiatives are especially important during the preparation phase at the beginning of transformations (Pereira et al. 2018). In the preparation phase, an awareness of systemic problems at the macro-level emerges, which inspires local actors to develop and implement sustainability initiatives on the micro-level as a response (Pereira et al. 2018). Initiatives can become organised into protoregimes that develop and explore alternatives to incumbent and unsustainable regimes that local actors seek to change or replace with their interventions and initiatives' impact (Geels 2002; Pereira et al. 2018; Loorbach et al. 2020). For decades, scholars have improved our understanding of local, bottom-up initiatives in sustainability transformations (e.g., Westley et al. 2006; Hawken 2007; Hopkins 2008; Westley et al. 2017). However, research on how these initiatives can actually realise transformations with their relations and amplification of their impact beyond themselves remains limited.

Lately, the question of how sustainability initiatives can amplify their impact has received increased interest (Moore et al. 2015; Bennett et al. 2016). Lam et al. (2020b) discuss the diverse actions that initiatives can deploy to purposively increase their transformative impact as 'amplification processes'. For example, initiatives can have more impact by increasing the number of initiatives to reach more people and places (e.g., an initiative opens a new office in another region) (Moore et al. 2015; Lam et al. 2020b). Understanding amplification processes is relevant for sustainability transformations because it can provide new insights on the building of proto-regimes and changes on the micro-, meso-, and macro-levels (Pereira et al. 2018).

One key aspect of applying amplification processes are the relations among local actors; and hence, their social networks (Frantzeskaki et al. 2014; Moore et al. 2015; Garrah et al. 2019). Social networks of local actors develop, protect, support, and share new ideas, knowledge, practices, and approaches that can lead to sustainability transformations (Moore and Westley 2011; Smith and Raven 2012). Different relations between local actors, such as sharing material resources or exchanging informal advice, constitute different networks and can lead to changes in different characteristics of a system, such as the parameters, feedbacks, design or intent of a system (Table 1) (Abson et al. 2017).

However, empirical studies aiming to better understand social networks of local actors and their initiatives that foster sustainability transformations remain scarce. In this regard, three aspects are of particular interest: (1) in which system characteristics can local actors jointly intervene to foster sustainability transformations?; (2) to what extent do amplification processes conducted by local actors relate to the system characteristics targeted when intervening in the system?; and (3) to what extent is the position in the social network of local actors associated with the interventions in system characteristics, and with the amplification processes used to foster transformative change?

In this paper, we seek to explore these three research gaps by applying a leverage points perspective. This will yield new insights on how local actors in social networks jointly intervene and leverage transformative change in systems. To address these questions, we analysed the social networks of non-governmental organizations (NGO) in Southern Transylvania, Romania, who are the main local actors working towards sustainability. Our first objective is to unravel whether the position of NGOs varies between different networks, representing relations that target different system characteristics (i.e., parameters, feedbacks, design, intent) to foster transformative change. Second, we show the associations between the amplification processes the NGOs applied and the NGOs' positions in different networks. 


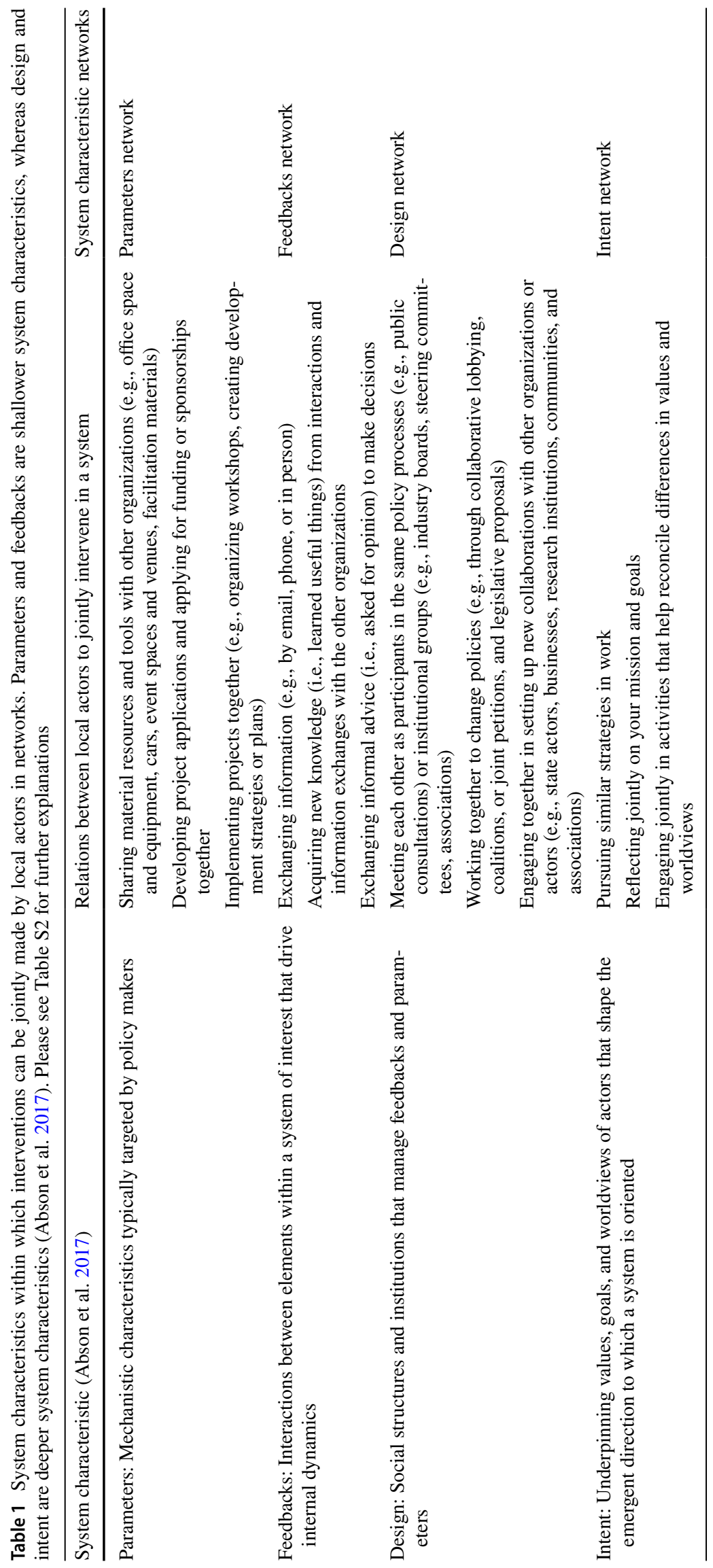




\section{Conceptual framework}

\section{A leverage points perspective in sustainability transformations research}

Within sustainability science, research on transformative change is increasing and has led to a sophisticated understanding of sustainability transformations (Loorbach et al. 2017; Köhler et al. 2019; Horcea-Milcu et al. 2020; Scoones et al. 2020). Scoones et al. (2020) conducted a review on conceptualizations of transformations and distinguish between three prominent approaches to transformations: structural, systemic, and enabling. While structural approaches study changes in the underlying foundations of society, politics, and the economy (e.g., capitalism, growth), systemic approaches apply systems thinking from the 1980 s to identify specific parts of systems (e.g., system elements, dynamics) as targets for focused change to foster sustainability (Scoones et al. 2020). Two prominent perspectives from scholarship on systemic approaches are the socio-technical and socialecological systems perspective that study the transformation of socio-technical or social-ecological systems (Berkes et al. 2002; Grin et al. 2010). Enabling approaches draw on the former two approaches, often adopt a transdisciplinary approach, and have a focus on purposefully creating the conditions to empower individuals and communities to foster transformative change on their own behalf (Scoones et al. 2020). Our study is aligned to transformations research that applies a mix of enabling and systemic approaches because we study the relations of local actors who jointly intervene in different characteristics of a system to foster change in a transdisciplinary research setting. To better understand in which characteristics of a system local actors intervene and which potential for transformative change these interventions entail, we apply a leverage points perspective.

The leverage points perspective contains a hitherto undervalued potential as a heuristic and practical tool for sustainability science to study intervention points in complex systems that can lead to transformations (Fischer and Riechers 2019). Leverage points are places to intervene in a system where a relatively small intervention in one part of a system can lead to relatively big changes in the whole system (Meadows 1999). The concept of leverage points stems from Donella Meadows' pioneering research on complex systems (Meadows et al. 1972). Meadows articulated 12 different leverage points (e.g., structure of material stocks and flows, length of delays, structure of information flows, goal of the system) (Meadows 1999). She separated them into "shallow" leverage points at which interventions are easy but they have a limited potential to bring about transformative change, and "deep" leverage points at which interventions are difficult but have a greater potential to bring about transformative change (Meadows 1999).

To reduce the complexity posed by the 12 leverage points, Abson et al. (2017) aggregated these 12 leverage points into four system characteristics that interventions can target: parameters, feedbacks, design, and intent of a system (from shallowest to deepest) (Table 1). Parameters are relatively mechanistic and modifiable characteristics (Abson et al. 2017). They are physical system elements (e.g., sizes of stocks), such as taxes, incentives, and standards that are typically addressed by policy makers. Feedbacks represent interactions between system elements (Abson et al. 2017). They drive system dynamics (e.g., reinforcing feedback loops) or return information for desired outcomes after an intervention (e.g., the effectiveness of a subsidy). The design of a system constitutes the social structures and institutions that organize feedbacks and parameters (e.g., structure of information flows, rules, power, and self-organisation) (Abson et al. 2017). The intent of a system comprises the underlying values, goals, and worldviews of actors that together are responsible for the system orientation (Abson et al. 2017).

Applying a leverage points perspective in sustainability transformations research helps us understand which places to intervene in complex systems exist (e.g., socio-technical or social-ecological systems) to bring about transformative change. This is especially relevant for systemic and enabling approaches to study transformations and contributes to at least four advantages according to Fischer and Riechers (2019). First, a leverage points perspective can bridge causal and teleological explanations of system change. Second, it highlights that deep leverage points have greater potential to lead to transformative change. Third, it enables the study of interactions between shallow and deep system changes. Fourth, it can be a methodological boundary object for academic and non-academic actors who work together in transformative transdisciplinary research settings.

\section{A leverage points perspective on social networks}

We apply the leverage points perspective to study how local actors driving sustainability initiatives for transformative change are organised in different social networks. We use the leverage points perspective since it provides conceptual guidance to identify where local actors can jointly intervene in a system based on different relations. These relations can address specific system characteristics (i.e., parameters, feedbacks, design or intent) (Table 1). For example, relations where local actors share material resources address the parameters of a system. Exchanging information, knowledge, and informal advice are relations that intervene in the feedbacks of 
a system since they represent interactions between different system elements that can drive dynamics (Table 1). When different local actors jointly try to change policies, they target the design of a system. Local actors address the intent of a system when they jointly reflect on their missions and goals, or engage in activities that help to reconcile differences in values and worldviews (Table 1).

In this study, we analyse three different relations per each system characteristic (Table 1). Here, we assume that we can aggregate the data that represent relations between local actors addressing the parameters, feedbacks, design or intent of a system. For example, since the exchange of information, knowledge, and informal advice intervenes in the feedbacks of a system, we aggregate these relations to depict the social network that targets the system characteristic of feedbacks (Table 1, Fig. 1). By depicting networks of the four system characteristics, we can gain a better understanding of which local actors are more or less relevant for intervening in deeper or shallower leverage points (Fig. 1). Earlier research has applied social network analysis to identify key actors that are relevant in natural resource governance (Prell et al. 2009; Hauck et al. 2016). In this study, we advance the application of social network analysis to study sustainability transformations by identifying key actors that intervene in specific system characteristics to foster transformative change.

\section{Amplification processes to foster sustainability transformations}

Amplification processes are relevant for sustainability transformations because they describe the diverse actions that local actors can deploy to purposively increase the transformative impact of sustainability initiatives (Lam et al. 2020b). The study of these different actions (i.e., amplification processes) can provide new insights on the role of sustainability initiatives and their impact during the preparation phase of transformations.

To characterize how local actors amplify the impact of their initiatives to foster transformative change, we analyse the role of different amplification processes in the four networks (i.e., parameters, feedbacks, design, intent). Lam et al. (2020b) have classified amplification processes into four groups (Table 2): (1) amplifying within, which comprises processes that increase the impact of one specific sustainability initiative by, for instance, prolonging or accelerating its impact; (2) amplifying out (dependent), which are processes that involve more people and places, or replicate an initiative in another context, but keep the dependency with the initial initiative; (3) amplifying out (independent), which initiates independent initiatives either by transferring an initiative to another place or by spreading the principles of an initiative to a new initiative in another place; and (4) amplifying beyond, which are processes that increase impact by scaling up, i.e., changing higher institutional levels such

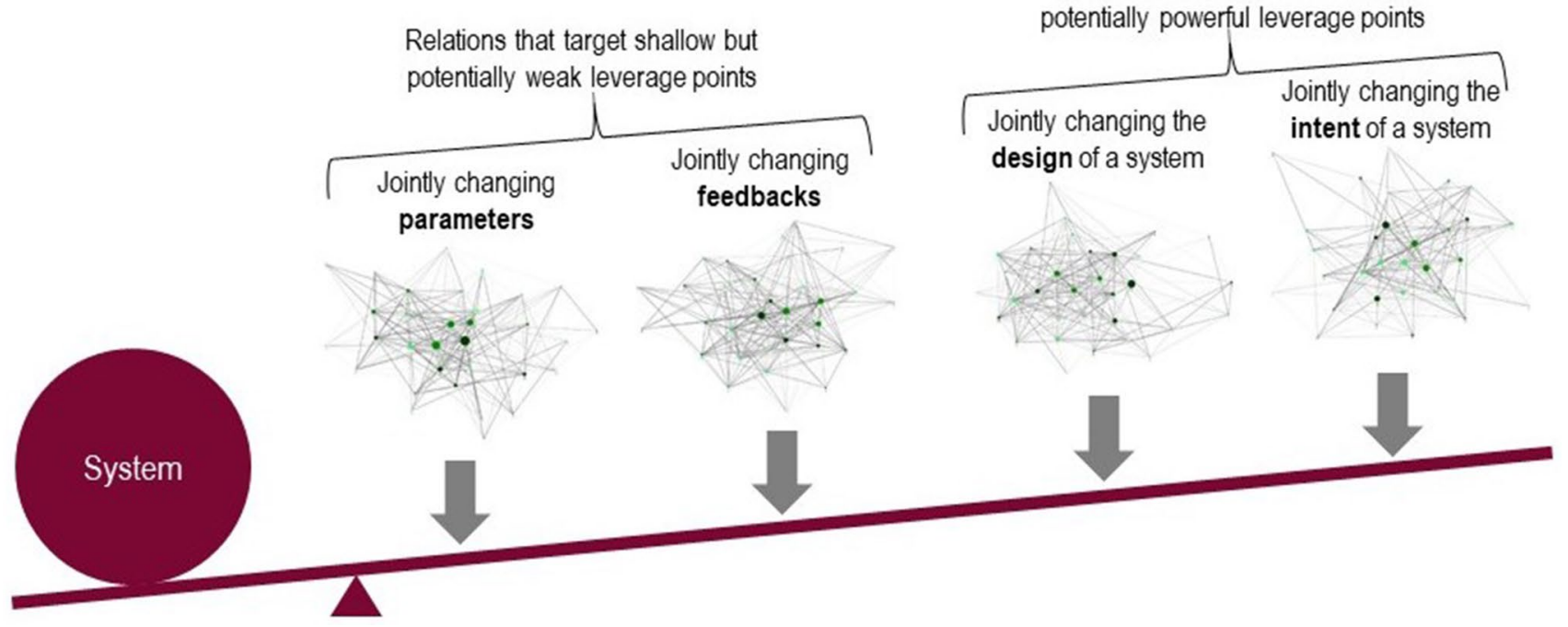

Relations that target deep and potentially powerful leverage points

Relations that target shallow but potentially weak leverage points

Fig. 1 A leverage points perspective on social networks based on Abson et al. (2017), Fischer and Riechers (2019), and Meadows (1999). Relations between actors in networks (green dots $=$ actors, grey lines $=$ relations) can have different realms of lever to change a system and can be aggregated to the system characteristics that they address (i.e., parameters, feedbacks, design, intent of a system). Each node represents an NGO and the node size represents the between- ness score. The node colour shows how many different groups of amplification processes are applied by the NGOs (i.e., dark green $=4$, green $=3$, turquoise $=2$, light-green $=1$, grey $=0$ ). Ties represent relations between NGOs and the thickness of the ties shows the extent of the relation (i.e., very thick $=$ high, thick $=$ moderate, thin $=$ low). (Figure is adopted from an earlier version with permission by David J. Abson) 
Table 2 Groups of amplification processes based on Lam et al. (2020b) and corresponding survey questions

\begin{tabular}{ll}
\hline Groups of amplification processes & Survey question \\
\hline Amplifying within & $\begin{array}{c}\text { Have you done something to extend the lifetime of your initiatives or to speed up the way your initiatives } \\
\text { create impact? }\end{array}$ \\
Amplifying out (dependent) & Have you expanded the impact of your initiatives to other places? \\
Amplifying out (independent) & Have your initiatives been the inspiration to create independent similar initiatives at other places? \\
Amplifying beyond & $\begin{array}{c}\text { Have your initiatives influenced rules, laws, or underlying values, which inspire people to live in a different } \\
\text { way? }\end{array}$ \\
\hline
\end{tabular}

as policies and rules, or by scaling deep, i.e., changing mindsets or values. Thus, amplification processes describe the diverse actions that local actors can deploy to increase the impact of their initiatives (Moore et al. 2015; Bennett et al. 2016; Gorissen et al. 2018; Lam et al. 2020b).

To amplify impact, initiatives can intervene in different leverage points. For instance, to protect biodiversity, a conservation initiative might aim to change policies at higher institutional level (i.e., amplifying beyond), which is an intervention in the design of a system. Therefore, we assume that there are associations between applied amplification processes and the central role of local actors in different networks (i.e., centrality metrics) that intervene in different system characteristics. Dismantling these associations can provide insights into which relations are potentially more relevant for the application of specific amplification processes to intervene in a specific system characteristic. For example, we hypothesise that local actors who replicate their initiatives to other places (i.e., amplifying out (dependent)) are presumably those in central positions in the feedbacks network since they potentially exchange information or provide informal advice (i.e., feedbacks system characteristic).

\section{Case study: Non-governmental organizations acting for sustainability in Southern Transylvania, Romania}

Southern Transylvania spreads over 270,000 ha and is home to great natural and cultural diversity, making it one of the largest areas of farmland with high natural value in the European Union. Yet, its multifunctional landscapes are threatened by numerous changes happening within and outside this region, such as draining migration, tenure changes, and the influence of the global markets. Navigating these changes while conserving the unique heritage, and responding to global pressures and local aspirations have created a delicate balancing act (Horcea-Milcu et al. 2018).

Many local NGOs have responded to the regional sustainability challenges in Transylvania, such as the loss of biodiversity or cultural heritage. They act through numerous initiatives dealing with nature and cultural heritage conservation, supporting small-scale farming, eco-tourism, or rural community development (Fig. 2) (Fischer et al. 2019; Lam et al. 2020a). For example, the Mihai Eminescu Trust is an NGO that leads different initiatives to conserve and regenerate villages and communities in Transylvania by, for instance, revitalizing traditional handicrafts, or supporting peasants to access communal pasture land for their livestock (www.mihaieminescutrust.org). Another example is Fundatia Adept, an NGO focused on biodiversity conservation and rural development which supports the production of cheese on village level, or implements bike trails to support eco-tourism in the region (www.fundatia-adept.org).

These initiatives are locally relevant and lead the local pathway to sustainability transformation according to an agreed upon target vision (Hanspach et al. 2014; Fischer et al. 2015). The target vision was co-developed and covalidated in scenario building exercises with local actors at the end of 2012. During this exercise, four alternative scenarios for the future of Southern Transylvania in 2050 were developed (Hanspach et al. 2014). The scenario named "Balance Brings Beauty" was widely agreed to be the most preferred scenario for the region by a range of local actors (Nieto-Romero et al. 2016). We have later confirmed and validated this preference during outreach activities with local communities in 2014. Balance Brings Beauty describes a target vision where local people have the possibilities to take advantage of opportunities through collaboration and joint initiatives, in a context of pro-environmental conditions through national and supra-national policy (Hanspach et al. 2014). Target visions are important to align different efforts that foster sustainability in strategies, create momentum for action, and get the attention of and commitment from diverse actors (Frantzeskaki et al. 2014; Wiek and Lang 2016).

Yet, a study on the role of visioning in fostering collective action for sustainability in Southern Transylvania highlighted the lack of collaboration between organisations and lack of information exchange as barriers to reaching the vision (Nieto-Romero et al. 2016). Hence, supporting and enabling the actions and initiatives spearheaded by these local actors of change is a matter of networking and amplifying the impact of their initiatives (Fischer et al. 2019; Lam et al. 2020a). For this study, we explore the relations 

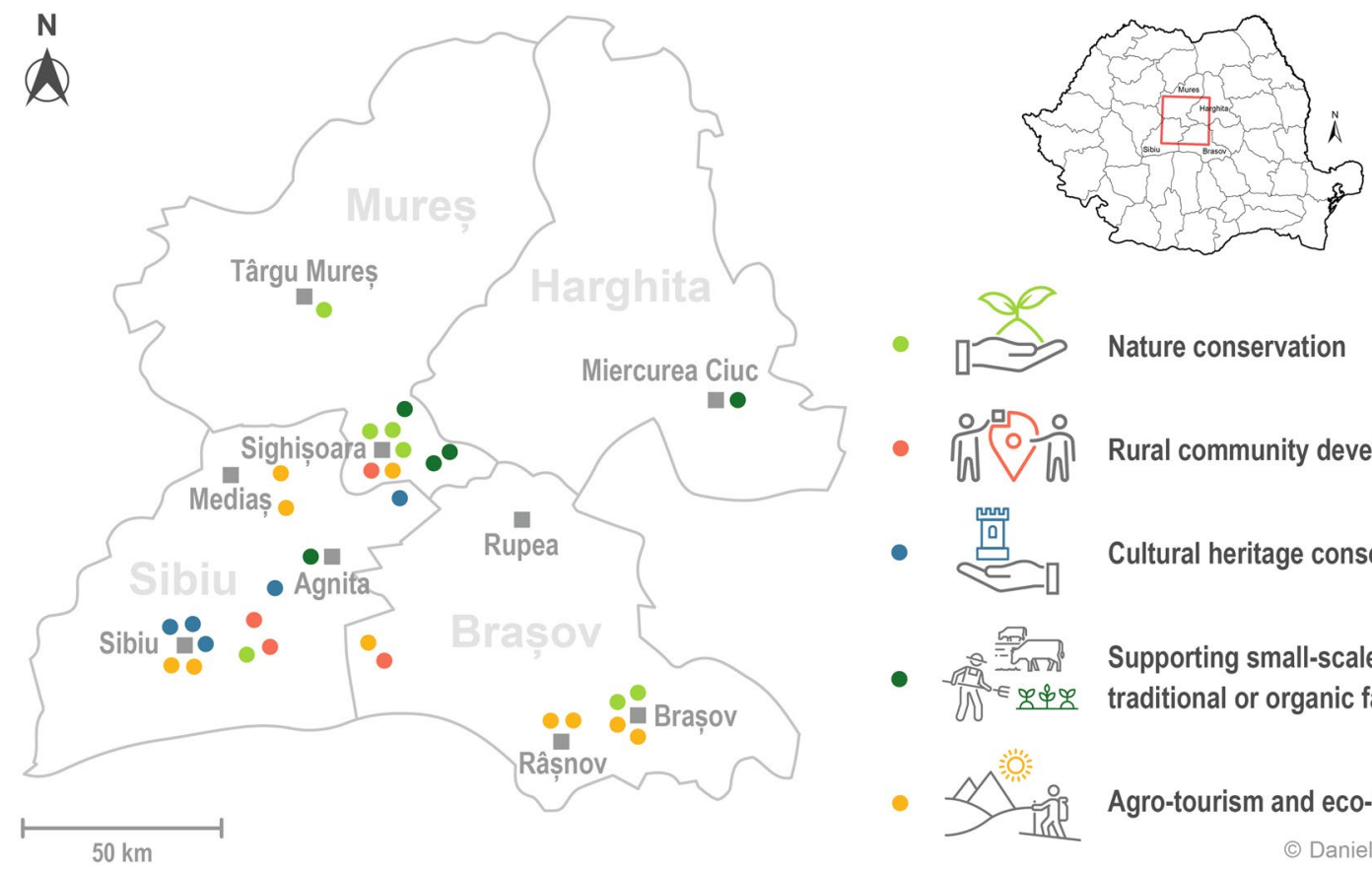

Rural community development

Cultural heritage conservation

Supporting small-scale,

traditional or organic farming

Agro-tourism and eco-tourism

(C) Daniela Peukert

Fig. 2 Map showing the main location of 31 non-governmental organizations (NGO) trying to foster sustainability in Southern Transylvania (one main location of an NGO is not in Southern Transylvania) in the fields of nature conservation, rural community devel-

between 32 NGOs who lead sustainability initiatives in Southern Transylvania (Fig. 2; Table S1 provides anonymous information about the work of the 32 NGOs).

\section{Methods}

\section{Social network analysis}

Social network research defines relations as ties, actors as nodes, and characteristics of actors as attributes (e.g., number of members in an organization, geographical regions in which an organization is working) (Prell 2011). This field of research is manifold, but generally provides insights on three levels: the individual level (e.g., looking at how central an actor is in a network), the dyadic level (i.e., identifying microstructures of groups of actors in a network), and the network level (i.e., analysing network properties, such as density) (Borgatti et al. 2009; Salpeteur et al. 2017).

Social network analysis has been used to gain understanding of natural resource governance and human-nature relations. Some examples include identifying key actors for the management of natural resources (Bodin and Prell 2011; Hauck et al. 2016), following the transmission of local ecological knowledge (Salpeteur et al. 2017), and opment, cultural heritage conservation, small-scale farming, and agro-tourism/eco-tourism (Map from Daniela Peukert in Fischer et al. (2019)). The colours indicate the main domain of activity of each initiative

identifying telecoupled processes by which some actors exert more power than others in ecosystem service management (Martín-López et al. 2019). So far, the application of social network analysis has brought four major contributions to the understanding of natural resource governance (Salpeteur et al. 2017). First, social network analysis identifies the characteristics of actors that are relevant to create the network structures (i.e., centrality, brokering ability) (Prell et al. 2009). Second, social network analysis reveals the relations and processes that can connect actors in a network (e.g., collaboration, decision making) (Rico García-Amado et al. 2012). Third, social network analysis identifies structural network characteristics that connect actors which lead to different natural resource management regimes (Bodin and Crona 2009). Finally, social network analysis reveals the multi- and cross-scale relations between actors that occur in natural resource governance and management of human-nature relations (Cohen et al. 2012).

We explored the potential of social network analysis for sustainability transformations research to generate new insights, such as the identification of key actors for collaborations and interventions to address different characteristics of a system. For this, we created four depictions of social networks that illustrate the relations between sustainability initiatives through which they jointly intervene 
in the four system characteristics parameters, feedbacks, design, and intent (Table 1).

\section{Data collection}

We collected data from 32 NGOs that seek to foster sustainability in Southern Transylvania by realizing diverse sustainability initiatives (Fig. 2; Table S1). We invited 32 NGOs to participate in an online survey from December 2017 until February 2018 of which 30 NGOs responded. The survey was sent in almost all cases to persons with who we had working experiences and who participated in previous meetings. From 26 NGOs, we received one survey back. For the remaining four NGOs, we received two or three surveys that we aggregated into one dataset representing one NGO. Therefore, the final dataset contained information collected from 30 NGOs.

The online survey comprised questions about (1) the NGOs' relations to other NGOs according to the different leverage points (see "A leverage points perspective in sustainability transformations research" and "A leverage points perspective on social networks", Table 1, Table S2) and (2) the amplification processes they apply to increase the impact of their initiatives to foster sustainability (see "Amplification processes to foster sustainability transformations", Table 2).

To examine the networks from a leverage points perspective, we developed 12 questions that referred to the four system characteristics that leverage points can address (Meadows 1999; Abson et al. 2017) (Table S2). These 12 questions on relations were contextualized through our previous work and long-term experience with the NGOs in Southern Transylvania (Table 1) (Hanspach et al. 2014; Nieto-Romero et al. 2016; Horcea-Milcu et al. 2018). For example, the question "To what extent have you shared material resources and tools with the following organizations (e.g., office space and equipment, cars, event spaces and venues, facilitation materials)?" referred to a shallower leverage point of parameters since it refers to constants, parameters, and numbers of the system. Table $\mathrm{S} 2$ outlines the questions used in the survey. Each question asked the NGOs to rate the strength of their relations to the other NGOs over the past 5 years concerning their work on sustainability in Southern Transylvania with the following response options: not at all (0), low extent (1), moderate extent (2), high extent (3), and "I don't know" (Table S2). We developed all questions in accordance to the four types of system characteristics (i.e., parameters, feedbacks, design, and intent), which means that we clustered the answers into the four system characteristics (Table 1).

To examine the node attribute "applied amplification processes", we asked four questions related to the NGOs' actions to increase the impact of their sustainability initiatives. The four questions used asked about the four groups of amplification processes that can be applied by local actors to purposively increase the transformative impact of their initiatives, including amplifying within, amplifying out (dependent), amplifying out (independent), and amplifying beyond (see "Amplification processes to foster sustainability transformations". and Table 2 for the specific questions).

\section{Data analysis}

We used Gephi and NodeXL software to conduct the network analysis and visualisation (Bastian et al. 2009; Smith et al. 2010). We created four networks, one for each of the four system characteristics, i.e., parameters, feedbacks, design, and intent network (Fig. 1). We aggregated the answers of three questions related to each system characteristic by taking the highest perceived relation between NGOs. For instance, if the answers to three questions associated with a particular system characteristic were "1", "1", and " 3 ", then the highest perceived relation between NGOs to accomplish this system characteristic was " 3 ". We chose this approach because calculating an average would display false relations and taking the lowest would underestimate the extent of the relations. However, we are aware that taking the highest perceived relation might mean relations are overstated.

We calculated the weighted degree, betweenness, and eigenvector centrality for each of the NGOs (i.e., nodes) in the four networks (Table S3). Weighted degree measures the relations of one node to other nodes in the network (Freeman 1978), pondered by the weight of the relations (Barrat et al. 2004; Newman 2004). Thus, it provides information about the individual interconnectedness of each node to the network. Betweenness measures how often a node links other nodes that would otherwise be disconnected (Freeman 1978; Wasserman and Faust 1994). Nodes with higher betweenness exert more control over the network (Freeman 1978). Finally, eigenvector centrality measures the influence of a node in the network, weighted by the influence of its adjacent nodes (Bonacich 1972; Borgatti and Everett 1997). Because eigenvector takes into account the degree centrality of its adjacent nodes, this centrality metric can be interpreted as the future influence of a node (Prell 2011).

We tested whether differences in the centrality metrics (i.e., weighted degree, betweenness, eigenvector) occurred due to the different groups of amplification processes (i.e., amplification within, out (dependent), out (independent), beyond) applied by the NGOs in the four networks of parameters, feedbacks, design, and intent. We used the non-parametric Mann-Whitney U test to compare the centrality metrics between those NGOs that apply a particular group of amplification processes and those that do not apply them in each of the four networks. This provides insight into whether the centrality metrics of NGOs who applied 
a particular group of amplification processes were significantly different to those who did not apply this particular group of amplification processes. Prior to the Mann-Whitney $U$ test, data on centrality metrics were screened for outliers based on z-scores. Because only 30 of 32 NGOs participated in the survey, we kept the two NGOs that did not respond when calculating the centrality metrics and creating the networks, but left them out when we tested for differences of the centrality metrics among the four groups of amplification processes.

\section{Results}

\section{Social networks of NGOs working on sustainability in Southern Transylvania}

We created four networks that represent the relations between 32 NGOs when realizing actions to foster sustainability in Southern Transylvania (Fig. 3). Each network represented relations that target different system characteristics, i.e., parameters, feedbacks, design, and intent. We found that while some NGOs had high centrality metrics across all four networks (e.g., N18 and N20 for weighted degree and betweenness), other NGOs had high weighted degree, betweenness, or eigenvector in one particular network. Table S3 presents all centrality metrics (i.e., weighted degree, betweenness, eigenvector) for each NGO in the four networks of parameters, feedbacks, design, and intent.

Concerning weighted degree (see "Data analysis"), N18 and N20 were among the NGOs with the highest weighted degree scores in all four networks (Table S3). Thus, N18 and N20 had a high interconnectedness in all four networks, meaning that they had a key role when intervening in the system to foster transformative change in Southern Transylvania. Three NGOs had highest weighted degree scores in three networks, which were N19 in feedbacks, design, and intent; N24 in parameters, feedbacks, and design; and N29 in parameters, feedbacks, and intent.
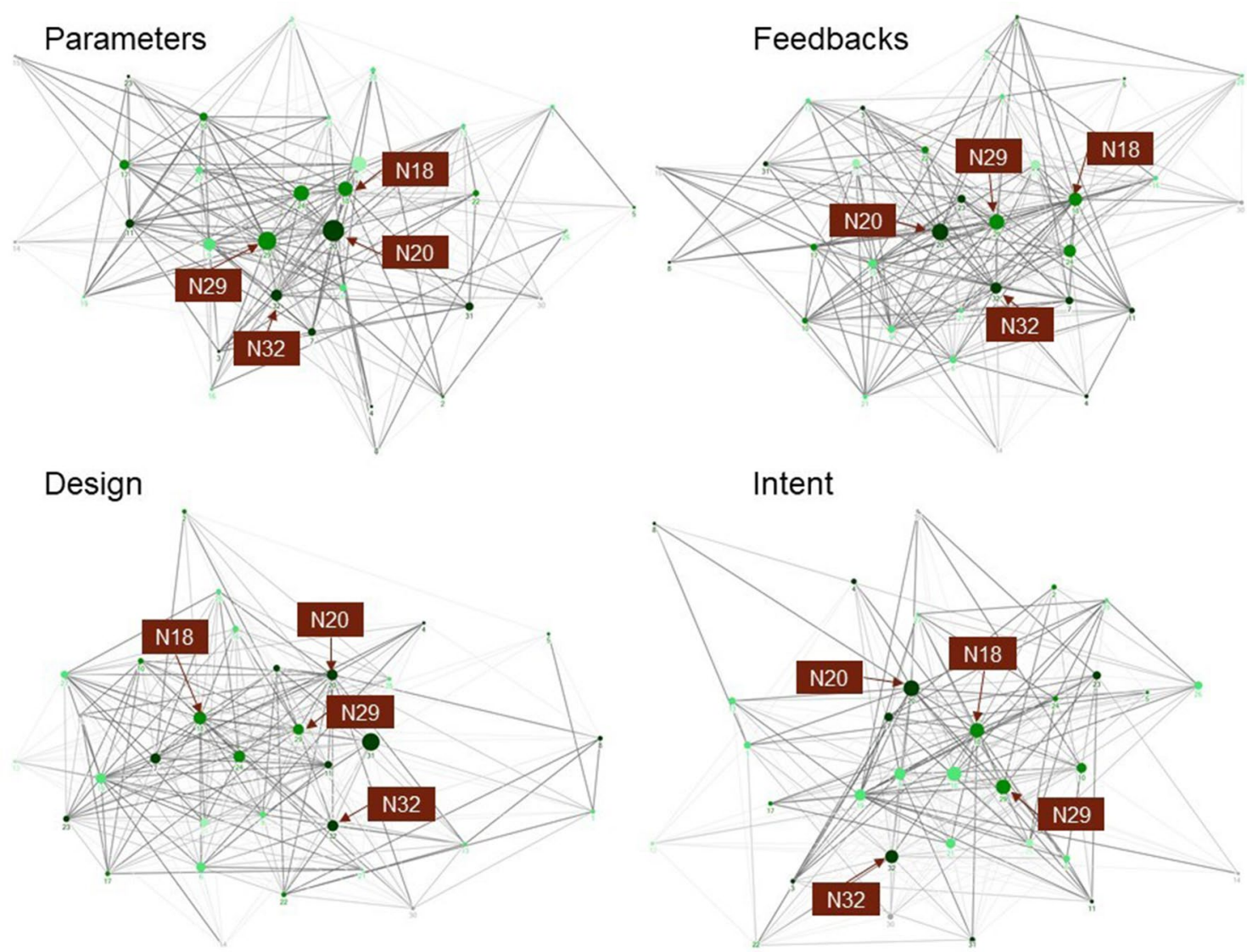

Fig. 3 Parameters, feedbacks, design, and intent network of 32 nongovernmental organizations (NGO) working on sustainability in Southern Transylvania, Romania. Each node represents an NGO and the node size represents the betweenness score. The node color shows how many different groups of amplification processes are

applied by the NGOs (i.e., dark green $=4$, green $=3$, turquoise $=2$, light-green $=1$, grey $=0$ ). Ties represent relations between NGOs and the thickness of the ties shows the extent of the relation (i.e., very thick $=$ high, thick $=$ moderate, thin $=$ low) 
Another three NGOs had highest weighted degree scores only in network, which were N7 in design, N9 in intent, and N25 in parameters network (Table S3).

Concerning betweenness (see "Data analysis"), two NGOs were among the NGOs with the highest betweenness scores in all four networks, which were N20 and N18 (Fig. 3, Table S3). This means that N20 and N18 exerted high control over the four networks, reinforcing their key role to foster transformative change in Southern Transylvania. Three NGOs had highest betweenness scores in three networks, which were N29 in parameters, feedbacks, and intent; N24 in parameters, feedbacks, and design; and N32 in feedbacks, design and intent. Three NGOs had highest betweenness score only in one network, which were N25 in parameters, N31 in design, and N16 in intent (Fig. 3, Table S3).

Concerning eigenvector (see "Data analysis"), only N29 had highest eigenvector scores in all four networks (Table S3). Thus, N29 will potentially have future influence when intervening in the system at the level of parameters, feedbacks, design, and intent in Southern Transylvania. Four NGOs had highest eigenvector scores in three networks. N20 had high eigenvector scores in parameters, feedbacks, and intent; N24 had high eigenvector scores in parameters, feedbacks, and design; and N18 and N32 had high eigenvector scores in feedbacks, design, and intent. N9 had highest eigenvector scores in two networks, which were parameters and intent. Two NGOs had highest eigenvector scores only in one network, which were N25 in parameters and N31 in design (Table S3).

\section{Comparison of centrality metrics between groups of amplification processes}

Of the 30 NGOs that answered our survey, 25 NGOs expressed that they increased the impact of their sustainability initiatives through amplifying within, 20 NGOs through amplifying out (dependent), 18 NGOs through amplifying out (independent), and 19 NGOs through amplifying beyond (Table S4). Looking at how many different groups of amplification processes were applied by each NGO revealed that nine NGOs applied all four, eight NGOs applied three, ten NGOs applied two, two NGOs applied one, and only one NGO applied none (Table S4).

We found significant differences in centrality metrics between cases when NGOs applied or did not apply a group of amplification processes in the networks of parameters, feedbacks, and design (Figs. 4-6). In the following, we list

\section{Parameters network}

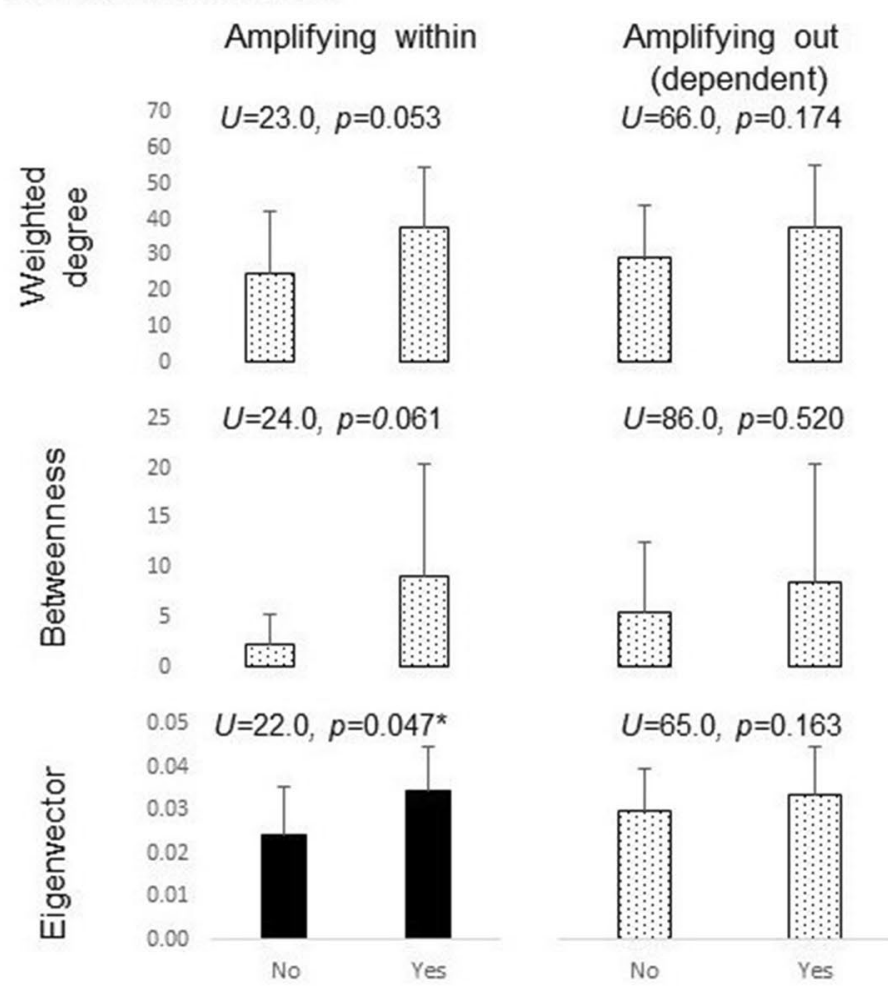

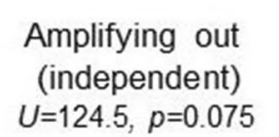

$U=124.5, p=0.075$
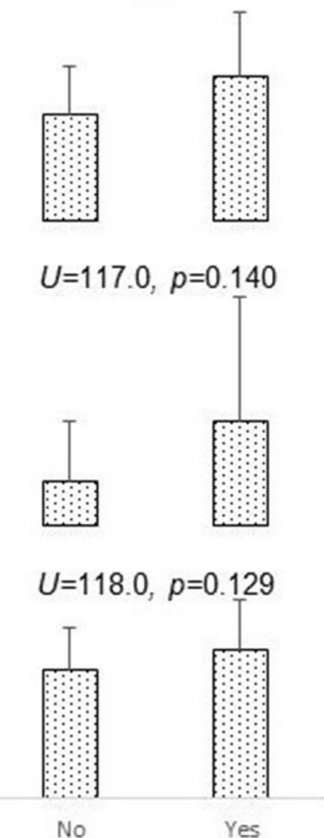

Amplifying Beyond

$U=90.5, p=0.427$

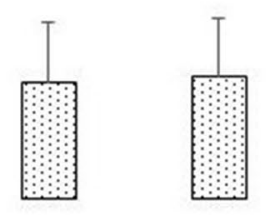

$U=105.0, p=0.685$

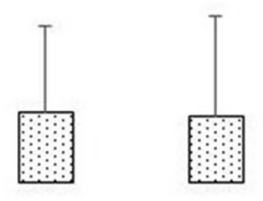

$U=98.0, p=0.564$

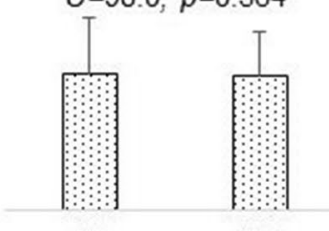

No Yes
Fig. 4 Results of Mann-Whitney U test for the parameters network: each graph shows if there was a significant difference between the centrality metrics (e.g., weighted degree) of NGOs who applied a particular group of amplification processes (e.g., amplifying within, yes) or not (e.g., amplifying within, no). Bars are coloured black if $\mathrm{p}<0.05$ 
the significant differences between those cases when NGOs applied or did not apply a group of amplification processes.

We found that eigenvector was higher when NGOs applied amplifying within than when NGOs did not apply it (parameters network: $U=22.0, p=0.047$ (Fig. 4); feedbacks network: $U=21.0, p=0.041$ (Fig. 5); design network: $U=20.0, p=0.036$ (Fig. 6)). Thus, NGOs who stabilized and sped up the impact of their sustainability initiatives (i.e., amplifying within) had higher eigenvector scores in the parameters, feedbacks, and design networks than NGOs that did not amplify within.

In the feedbacks network, we found that the weighted degree score was higher for NGOs that applied processes of amplifying out (dependent) and amplifying out (independent) than NGOs that did not (amplifying out (dependent): $U=51.0, p=0.047$; amplifying out (independent): $U=133.0, p=0.033$ (Fig. 5)). Thus, NGOs who expanded the impact of their initiatives to other places (i.e., amplifying out (dependent)), or were the inspiration to create similar, independent initiatives at other places (i.e. amplifying out (independent)) presented higher weighted degree scores in the feedbacks network than NGOs that did not amplify out at all.

\section{Feedbacks network}
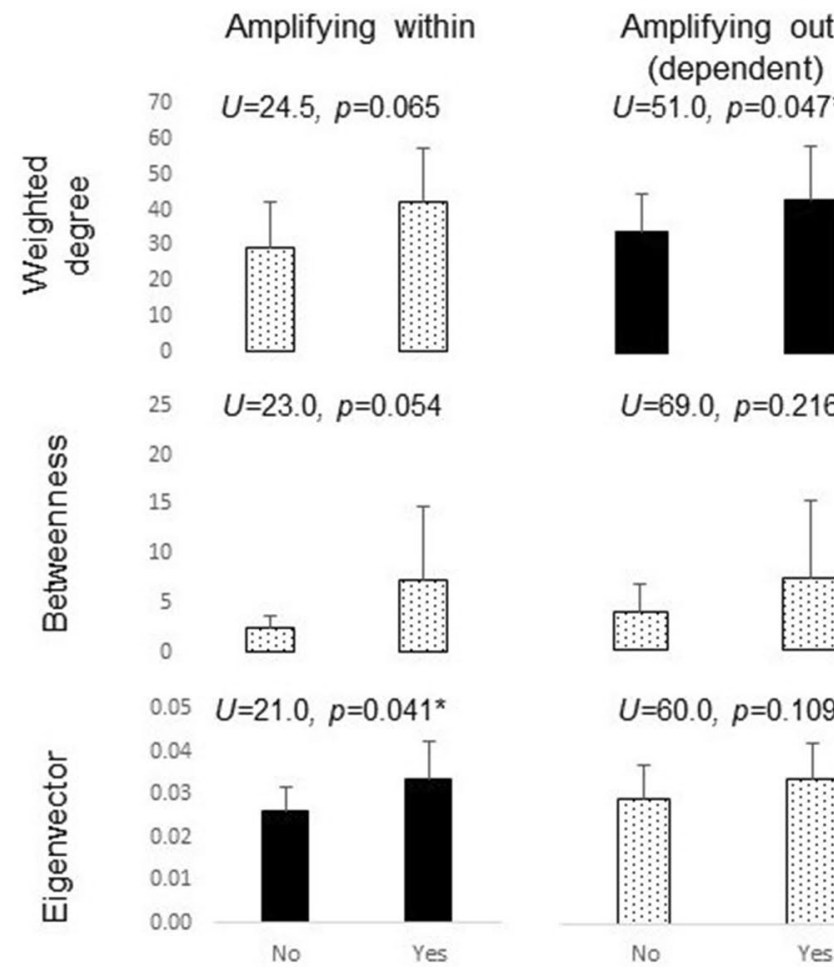

Fig. 5 Results of Mann-Whitney U test for the feedbacks network: each graph shows if there was a significant difference between the centrality metrics (e.g., weighted degree) of NGOs who applied a
In the design network, we found that the NGOs who amplified out (independent) had higher weighted degree and betweenness scores than NGOs that did not apply this amplification process (weighted degree: $U=135.0, p=0.027$; betweenness: $U=139.0, p=0.017)$. This result means that NGOs that inspired the creation of independent similar initiatives in other places (i.e., amplifying out (independent)) presented higher weighted degree (i.e., interconnectedness) and betweenness scores (i.e., control in the network) in the design network than NGOs who did not amplify out (independent). We also found that NGOs who amplified within presented higher betweenness scores than NGOs who did not apply this amplification process $(U=21.0 ; p=0.041)$ (Fig. 6). This means that NGOs who stabilised and sped up the impact of their sustainability initiatives (i.e., amplifying within) presented higher betweenness scores (i.e., control over the network) in the design network than those NGOs who did not amplify within.

Finally, we did not find differences in the centrality metrics in the intent network among the different groups of amplification processes applied by NGOs (Fig. 7).

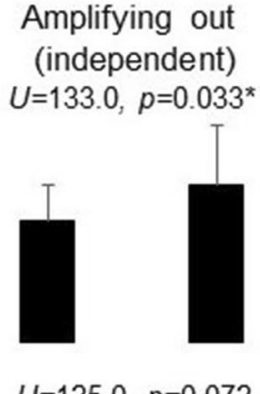

Amplifying Beyond

$U=83.0, p=0.298$

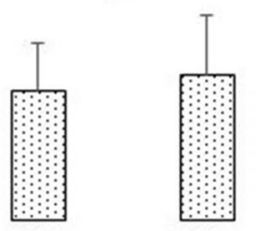

$U=98.0, p=0.564$
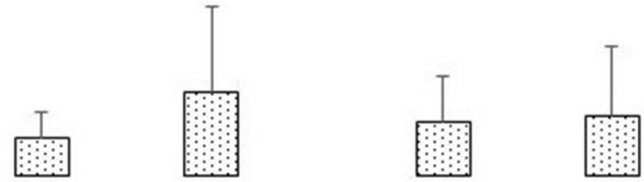

$U=118.0, p=0.129$

$U=98.0, p=0.564$
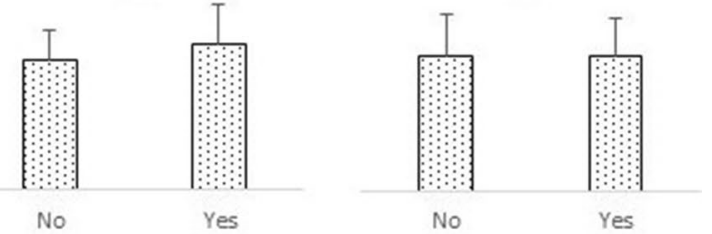

particular group of amplification processes (e.g., amplifying within, yes) or not (e.g., amplifying within, no). Bars are coloured black if $\mathrm{p}<0.05$ 


\section{Design network}

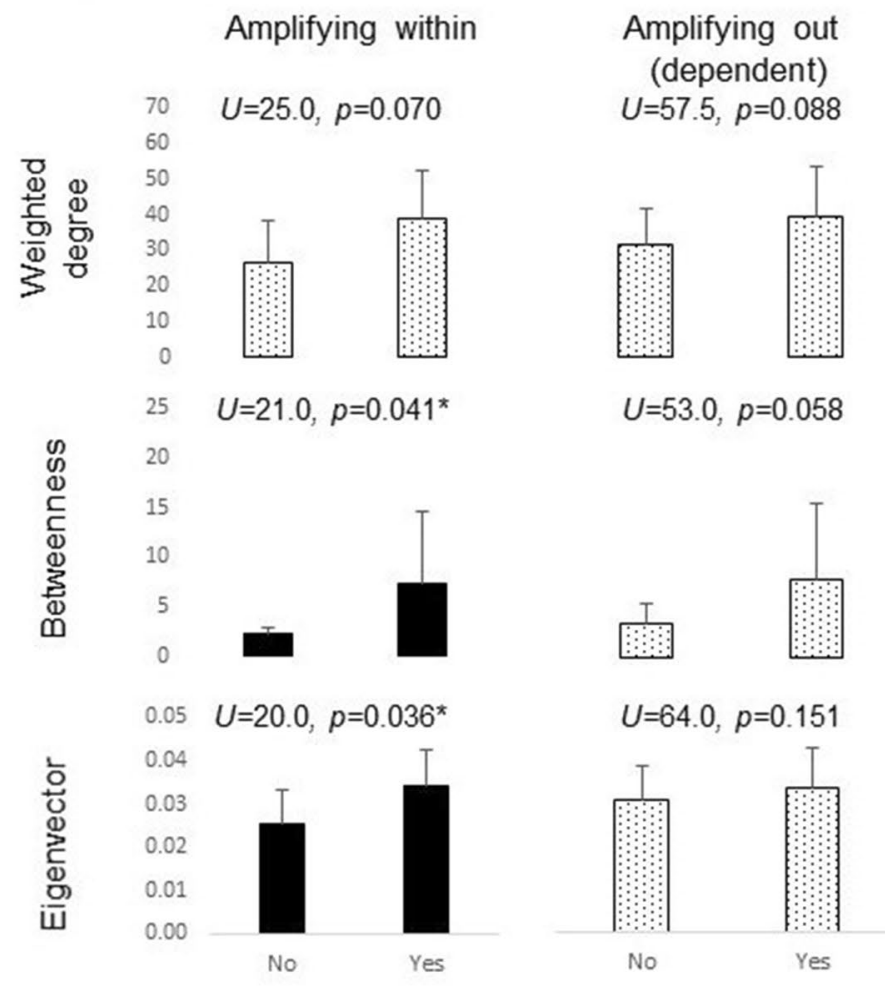

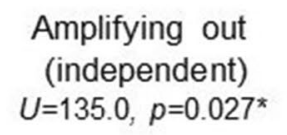

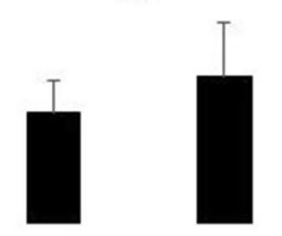

$U=139.0, p=0.017^{*}$

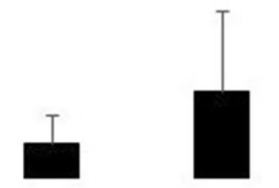

$U=122.0, p=0.094$

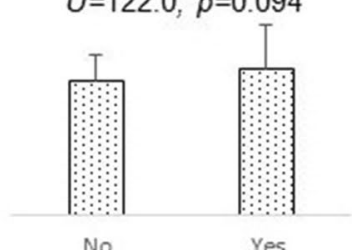

Amplifying Beyond

$U=61.0, p=0.062$
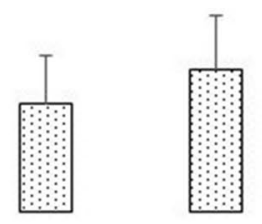

$U=65.0, p=0.088$
Fig. 6 Results of Mann-Whitney U test for the design network: each graph shows if there was a significant difference between the centrality metrics (e.g., weighted degree) of NGOs who applied a particular

\section{Discussion}

We illustrated how the application of a leverage points perspective on the social networks of NGOs in Southern Transylvania can contribute to identify NGOs with higher centrality metrics in networks that intervene in different system characteristics to foster sustainability. In addition, we showed that there are significant differences in centrality metrics of NGOs that applied or not applied amplification processes. In the following sections, we discuss three tentative insights that a leverage points perspective on social networks adds to sustainability science and transformations research: (1) local actors potentially play different central roles for intervening in different system characteristics, (2) local actors that increase their impact with amplification processes are potentially also more central in networks, and (3) implications for research and practice. These insights and discussion points are specific to our case study in Southern Transylvania. However, they can contribute to further exploration of the potential of conducting social network analyses using a leverage points perspective to understand sustainability transformations. group of amplification processes (e.g., amplifying within, yes) or not (e.g., amplifying within, no). Bars are coloured black if $\mathrm{p}<0.05$

\section{Local actors potentially play different central roles for intervening in different system characteristics}

From a leverage points perspective, local actors can intervene in systems by adjusting parameters and feedbacks (i.e., shallow system characteristics), or addressing the emerging design or intent of systems to foster sustainability (i.e., deep system characteristics) (Abson et al. 2017). Centrality metrics of local actors can be used to identify key actors for collaborations and interventions to foster sustainability, such as in the context of environmental resource governance (Prell et al. 2009). According to the centrality metrics of the NGOs from Southern Transylvania, our results indicate that there are potentially two types of local actors-in our case, NGOs-relevant for collaborations to intervene in shallow and deep system characteristics to foster sustainability (Fig. 3, Table S3). First, local actors who have high centrality metrics across networks that can intervene in both shallow and deep system characteristics. Second, local actors who have high centrality metrics only in specific networks that can address either shallow or deep system characteristics.

Regarding the first group of local actors, we found that the three NGOs N18, N20, and N29 had high scores of 


\section{Intent network}

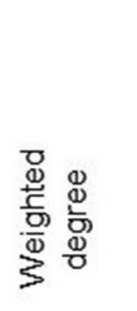

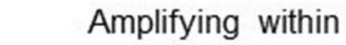

$60 . \quad U=36.0, p=0.225$

50

40

30
20

20
10

0

25

品

m.

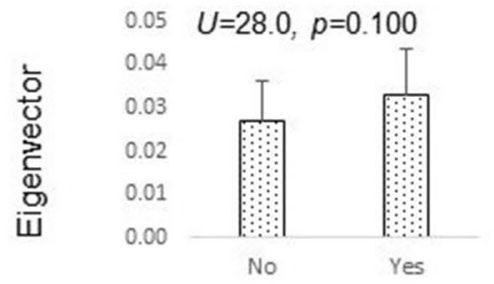

Amplifying out

(dependent)

$U=69.0, p=0.215$
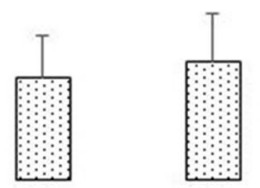

$U=76.0, p=0.329$
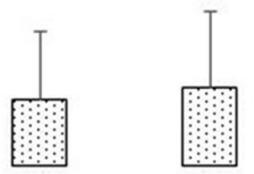

$U=65.0, p=0.163$

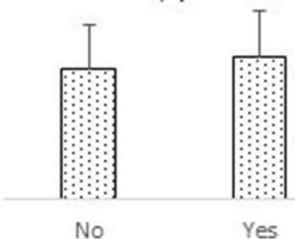

Amplifying out
(independent)
$U=120.5, p=0.106$

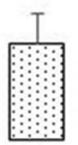

$U=111.0, p=0.212$

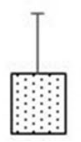

$U=117.0, p=0.140$

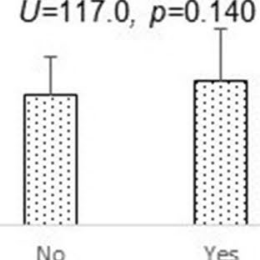

No
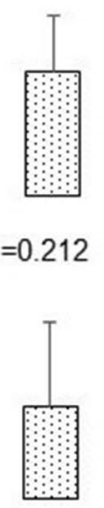

Amplifying Beyond

$U=68.0, p=0.112$
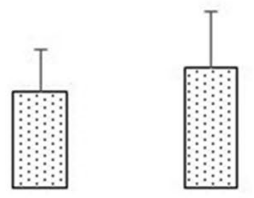

$U=78.0, p=0.225$
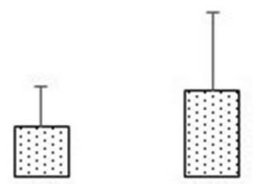

$U=82.0, p=0.283$

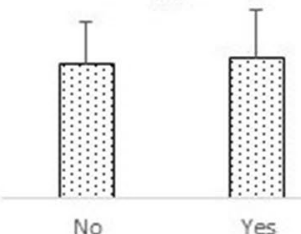

Fig. 7 Results of Mann-Whitney U test for the intent network: each graph shows if there was a significant difference between the centrality metrics (e.g., weighted degree) of NGOs who applied a particular

centrality metrics in all four networks (i.e., at least one high centrality metric per network) and that N32 also had high centrality metrics in the feedbacks, design, and intent networks (Table S3) (Hauck et al. 2016; Abson et al. 2017). This means that the four NGOs N18, N20, N29, and N32 were highly interconnected in the networks that addressed the parameters (e.g., sharing of resources), feedbacks (e.g., exchanging information), design (e.g., working together to change policies), and intent (e.g., reconciling differences in values and worldviews) of the system Southern Transylvania (Table S3). These results confirm earlier research on sustainability in Southern Transylvania that found that the NGOs behind these four nodes are the most active NGOs that foster sustainability in the areas of Mureș, Brașov, and Sibiu (Hanspach et al. 2014; Lam et al. 2020a). The projects of $\mathrm{N} 20, \mathrm{~N} 29$, and $\mathrm{N} 32$ are diverse and include establishing outdoor tourist infrastructures, conserving cultural built heritage, offering trainings to maintain traditional handicraft, supporting small-scale farmers, and conserving nature. Moreover, N18 is an umbrella organization that connects different eco-tourist activities of other NGOs in the region. All four NGOs have high scores for betweenness and/or eigenvector in the feedbacks, design, and intent networks (Fig. 3, Table S3). This means that group of amplification processes (e.g., amplifying within, yes) or not (e.g., amplifying within, no). Bars are coloured black if $\mathrm{p}<0.05$

these NGOs exert high control (i.e., betweenness) over the networks that target the feedbacks, design, and intent of the system Southern Transylvania, and have high potential to be key actors in the future (i.e., eigenvector). Although these four NGOs drive different sustainability initiatives (e.g., restoration of cultural built heritage, conservation of biodiversity), they share the vision of fostering sustainability in Southern Transylvania through their local initiatives (Lam et al. 2020a). These NGOs share their intensive local work with communities and small-scale farmers to foster well-being while conserving the unique natural and cultural heritage of Southern Transylvania.

Our study also reveals that N24 plays a central role in the parameters, feedbacks, and design networks with high scores for weighted degree, betweenness, and eigenvector (Table S3). N24 is mostly active in the regions of Mureș and Sibiu and focuses on promoting the cultural and natural heritage of these areas by, for instance, connecting various initiatives from different NGOs by celebrating seasonal food products or reactivating and reinterpreting old traditions towards new practices. Organising such activities that connect other NGOs might be the reason for N24's high centrality metrics. 
Hauck et al. (2016) and Prell et al. (2009) use high centrality metrics of actors to identify key actors for collaborations and interventions, for example, in natural resource governance. The high centrality metrics of N18, N20, N24, $\mathrm{N} 29$, and $\mathrm{N} 32$, indicate that they are potentially key actors for collaborations and interventions to foster transformative change towards sustainability in shallow and deep leverage points in Southern Transylvania.

Regarding the second group of local actors, who have high centrality metrics only in specific networks, our study shows that these NGOs only play central roles (i.e., high centrality scores) in specific networks: e.g., N25 plays a central role in the parameters network, $\mathrm{N} 31$ in the design network, and N9 in the intent network (Table S3). This shows that some NGOs are essential to address specific system characteristics and thus are potentially key partners to intervene in specific characteristics of the system. For example, while N25 can be instrumental to share material resources and tools, N31 can be important to set up new collaborations with other organizations, and N9 can be supportive to reconcile differences in values and worldviews. Identifying the relevant partners for interventions in particular system characteristics is crucial for successful collaborations that foster sustainability transformations.

These results indicate that conducting social network analysis with a leverage points perspective to understand how local actors work together to foster sustainability in a system can shed light on the key roles that particular local actors have to intervene in specific system characteristics. Abson et al. (2017) and Dorninger et al. (2020) have said that most sustainability interventions tend to address shallower system characteristics and leverage points, which are easier to address but have limited potential for transformative change in comparison to addressing deeper system characteristics and leverage points. The application of social network analysis with a leverage points perspective can also indicate which local actors are able to mobilise actions that intervene in deeper leverage points. In addition, our study shows that some of the local actors with high centrality metrics in the networks related with deeper leverage points (i.e., design and intent) are also key actors for intervening in shallower leverage points (i.e., parameters and feedbacks). This might indicate that such local actors are essential to develop initiatives that foster change by intervening in both shallower and deeper system characteristics.

\section{Local actors that amplify their impact are potentially also more central in networks}

Literature on sustainability transformations highlights the importance of networks of local actors who apply amplification processes to increase the impact of their sustainability initiatives (Moore et al. 2015; Lam et al. 2020b). Our results show differences in the centrality metrics of NGOs that apply or not apply amplification processes (i.e., amplifying within, out (dependent), out (independent), beyond) in the networks of parameters, feedbacks, and design (Figs. 4, 5, 6). However, our study cannot provide insight into the level and strength of association between amplification processes and centrality metrics.

In this section, we discuss the following: (1) amplification processes and intervening in deeper system characteristics; (2) amplifying within and the future influence of NGOs; (3) amplification processes and the control over changing structures and institutions; and (4) amplifying out and the connectedness of NGOs.

First, we found a gradual increase of significant differences for the scores of centrality metrics between those NGOs that applied amplification processes and those that did not, from shallower to deeper networks (i.e., parameters to feedbacks to design). Surprisingly, we did not find any significant differences for the intent network which is probably because of the intangible nature of changing underpinning values, goals, and worldviews. In the case of Southern Transylvania, we found one significant difference for the parameters, three for the feedbacks, and four for the design network (Figs. 4, 5, 6). This gradual increase of significant differences potentially shows that the amplification of impact by NGOs in Southern Transylvania is presumably associated with successful interventions in deeper characteristics of the system (i.e., design). This could be either because NGOs that jointly intervene in the design of the system could also have more opportunities to amplify their impact, or because NGOs that amplify their impact are better able to influence deeper system characteristics. We found most significant differences for changing the design of a system, which referred to work together in the same policy processes or institutional groups, to change policies, or to set up new collaborations with other organizations (Table 1). This finding underlines the importance of amplifying impact of initiatives to change structures and institutions, which is a powerful system intervention and a recognized means to amplify impact (Abson et al. 2017; Gorissen et al. 2018).

Second, for the parameters, feedbacks, and design network, we found significant differences for the eigenvector scores between NGOs that amplify within and NGOs that did not (Figs. 4, 5, 6). This might mean that NGOs who try to stabilize and speed up the impact of their sustainability initiatives (i.e., amplifying within) will also be more relevant in the future (i.e., eigenvector) for changing the parameters (e.g., sharing material resources and tools), feedbacks (e.g., exchanging information), and design of the system (e.g., working together to change institutions and policies) in Southern Transylvania (Table 1, Table S4). This may be 
because actions to extend the lifetime of initiatives and speed up impact lead to longer and faster impact of local initiatives (i.e., applying amplifying within), which is relevant for having more impact in the future. This finding indicates the importance of actions to stabilize and speed up the impact of NGOs' sustainability initiatives to increase their influence to foster transformative change in the future in Southern Transylvania.

Third, we found significant differences in the betweenness scores between NGOs that amplify within and amplify out (independent), and those that did not in the design network (Fig. 6). This might signify that NGOs who stabilise and speed up the impact of their sustainability initiatives (i.e., amplifying within) and are the inspiration for creating new independent initiatives in other places (i.e., amplifying out (independent)) are more influential in changing structures and institutions in Southern Transylvania by, for example, working together with other actors to change policies (Table 1, Table S4). This insight indicates the potential importance of actions to stabilise and speed up the impact of sustainability initiatives (i.e., amplifying within) and of being the inspiration for other actors (i.e., amplifying out (independent)) to exert more control over relations that can change deeper system characteristics, such as structures and institutions in Southern Transylvania.

Fourth, we found significant differences for the weighted degree scores between NGOs that amplify out (independent) and those that did not in the feedbacks and design network. Moreover, we found differences in the weighted degree scores between NGOs that amplify out (dependent) and those that did not in the feedbacks network. This might mean that NGOs that aim to increase their impact in other places (e.g., by creating new initiatives) are also more connected with regards to exchanging information, knowledge, and informal advice. Additionally, this finding could signify that NGOs that are the inspiration for new initiatives in other places are also more connected with regards to participating in policy processes, working together with other actors to change policies, and setting up new collaborations. This potentially shows that NGOs who connect other NGOs with regards to the feedbacks and design of a system are also those who expand their impact to other places.

We conclude that these results provide tentative insights for a more differentiated understanding of why relations and networks are important for applying amplification processes to foster transformations. Our insights uncover that relations and networks are probably not important for applying amplification processes per se. Instead, they show that it potentially depends on the type of relation and network as well as the position of the local actor in the network. Based on our results from Southern Transylvania we hypothesise that NGOs that apply amplification processes are also those who have more capacity to intervene in the system characteristics of parameters, feedbacks, and design. Although we still need to explore the strength of these associations, we suggest that NGOs that apply amplification processes could be more relevant actors to collaborate with to intervene in the system of Southern Transylvania. More specifically, for intervening in deeper system characteristics, such as the social structures and institutions (i.e., design of a system), NGOs that increase their impact via amplifying within and amplifying out (independent) might be relevant partners.

\section{Implications for research and practice}

In our study, we explored the application of social network analyses of local actors with the leverage points perspective to understand sustainability transformations in Southern Transylvania. We suggest that this approach provides the following tentative contributions for sustainability science and transformations research: (1) identification of key actors that intervene in shallower and deeper leverage points; (2) empirical insights on relations and networks for amplification processes; and (3) future steps for practice and research.

First, our approach identifies key actors for intervening in specific or across system characteristics to foster transformative change towards sustainability. Recent research highlights the importance of local actors and their initiatives to foster sustainability transformations (Garrah et al. 2019). We exemplified how a leverage points perspective in a social network analysis unravels "where" (i.e., leverage points) local actors jointly intervene in a system by providing a heuristic and practical tool to structure relations according to the system characteristics that they address. In addition, we suggest that high centrality metrics can help to identify relevant key actors for collaborations and interventions to foster sustainability transformation in a similar way that has been suggested in natural resource governance (Prell et al. 2009). Our approach could also be useful in studies of environmental governance and management where the identification of key actors in fostering more sustainable governance and management systems is crucial (Hauck et al. 2016; Salpeteur et al. 2017). In addition, the suggested approach is potentially helpful for sustainability transformations research since it can support the identification of potential partners (e.g., for government, academia) for specific system interventions (e.g., in deep leverage points). It also has the potential to enable research to explore how to best support local actors in their work on specific system characteristics.

Second, our approach provides first empirical insights on the role of relations and networks for amplification processes applied by local actors to increase the impact of their sustainability initiatives. Recent research highlights the importance of relations and networks between local actors 
trying to amplify their impact to foster sustainability (Moore et al. 2015; Garrah et al. 2019). Our results reveal significant differences for centrality metrics (i.e., weighted degree, betweenness, eigenvector) of NGOs in Southern Transylvania that apply or do not apply amplification processes. Our findings suggest that specific amplification processes are potentially relevant for local actors who are more connected (e.g., for exchanging information by amplifying out (independent)), have more control (e.g., for setting up new collaborations by amplifying within), or increase their future relevance (e.g., for implementing projects together by amplifying within) in a network.

Finally, substantial future research is necessary to further explore the potential of a leverage points perspective on social networks. For instance, it is crucial to better understand how microstructures (e.g., cliques) change across the parameters, feedbacks, design, and intent networks (Salpeteur et al. 2017). This could provide a more detailed understanding of attributes from groups of actors targeting specific system characteristics. Other research could investigate how the network structures affect the ability of actors to intervene in different system characteristics (Bodin et al. 2006). This is interesting because it could show which network structures are conducive for interventions on different system characteristics.

\section{Conclusion}

Local actors who drive sustainability initiatives can form social networks that foster transformative change towards sustainability in their context. Using a leverage points perspective when applying social network analyses has the potential to show which local actors are relevant partners for specific interventions in shallow (i.e., parameters and feedbacks) and deep (i.e., design and intent) system characteristics to foster transformative change. It can also provide insights into the role and importance of actor attributes for intervening in different system characteristics, such as the application of different amplification processes to increase the impact of their sustainability initiatives. These tentative insights on how local actors jointly intervene in different system characteristics have the potential to inform sustainability transformations research about the identification of relevant key actors for collaborations and interventions.

Acknowledgements We are deeply grateful and feel privileged to work with all the local actors and organisations in Southern Transylvania. We thank Cristina Apetrei and David J. Abson for inspiring discussion on the topic of the manuscript. We thank Rebecca Laycock Pedersen for the valuable English editing. We thank two anonymous reviewers and the editor for their critical and insightful comments. This research is supported by the Volkswagenstiftung and the Niedersächsisches Ministerium für Wissenschaft und Kultur (Grant Number A112269).
This research draws on work undertaken in a large transdisciplinary research project (Leverage Points for Sustainability Transformation). The author(s) acknowledge and thank all project members for their ideas and input in the early stages of this work, even where they are not listed as authors. Full details of project members and their research are available at https://leveragepoints.org. David P. M. Lam has also been supported by a research fellowship granted by the Foundation of German Business (sdw). Andra-Ioana Horcea-Milcu acknowledges funding through the European Union's Horizon 2020 research and innovation programme under the Marie Sklodowska-Curie grant agreement number 840207 .

Funding Open Access funding enabled and organized by Projekt DEAL.

Open Access This article is licensed under a Creative Commons Attribution 4.0 International License, which permits use, sharing, adaptation, distribution and reproduction in any medium or format, as long as you give appropriate credit to the original author(s) and the source, provide a link to the Creative Commons licence, and indicate if changes were made. The images or other third party material in this article are included in the article's Creative Commons licence, unless indicated otherwise in a credit line to the material. If material is not included in the article's Creative Commons licence and your intended use is not permitted by statutory regulation or exceeds the permitted use, you will need to obtain permission directly from the copyright holder. To view a copy of this licence, visit http://creativecommons.org/licenses/by/4.0/.

\section{References}

Abson DJ, Fischer J, Leventon J, Newig J, Schomerus T, Vilsmaier $\mathrm{U}$, von Wehrden H, Abernethy P, Ives CD, Jager NW, Lang DJ (2017) Leverage points for sustainability transformation. Ambio 46:30-39. https://doi.org/10.1007/s13280-016-0800-y

Balvanera P, Calderón-Contreras R, Castro AJ, Felipe-Lucia MR, Geijzendorffer IR, Jacobs S, Martín-López B, Arbieu U, Speranza CI, Locatelli B, Harguindeguy NP, Mercado IR, Spierenburg MJ, Vallet A, Lynes L, Gillson L (2017) Interconnected place-based social-ecological research can inform global sustainability. Curr Opin Environ Sustain 29:1-7. https://doi.org/10.1016/j.cosus t.2017.09.005

Barnosky AD, Matzke N, Tomiya S, Wogan GOU, Swartz B, Quental TB, Marshall C, McGuire JL, Lindsey EL, Maguire KC, Mersey B, Ferrer EA (2011) Has the Earth's sixth mass extinction already arrived? Nature 471:51-57. https://doi.org/10.1038/nature09678

Barrat A, Barthélemy M, Pastor-Satorras R, Vespignani A (2004) The architecture of complex weighted networks. Proc Natl Acad Sci USA 101:3747-3752. https://doi.org/10.1073/pnas.0400087101

Bastian M, Heymann S, Jacomy M (2009) Gephi: an open source software for exploring and manipulating networks. Third Int AAAI Conf Weblogs Soc Media. https://doi.org/10.1136/ qshc. 2004.010033

Bennett EM, Solan M, Biggs R, McPhearson T, Norström AV, Olsson P, Pereira L, Peterson GD, Raudsepp-Hearne C, Biermann F, Carpenter SR, Ellis EC, Hichert T, Galaz V, Lahsen M, Milkoreit M, Martin-López B, Nicholas KA, Preiser R, Vince G, Vervoort JM, Xu J (2016) Bright spots: seeds of a good anthropocene. Front Ecol Environ 14:441-448. https://doi.org/10.1002/fee.1309

Berkes F, Colding J, Folke C (eds) (2002) Navigating social-ecological systems. Cambridge University Press, Cambridge

Bodin Ö, Crona BI (2009) The role of social networks in natural resource governance: what relational patterns make a difference? 
Glob Environ Chang 19:366-374. https://doi.org/10.1016/j.gloen vcha.2009.05.002

Bodin O, Prell C (eds) (2011) Social networks and natural resource management. Cambridge University Press, Cambridge

Bodin Ö, Crona B, Ernstson H (2006) Social networks in natural resource management: what is there to learn from a structural perspective? Ecol Soc 11:r2

Bonacich P (1972) Factoring and weighting approaches to status scores and clique identification. J Math Sociol 2:113-120. https://doi. org/10.1080/0022250X.1972.9989806

Borgatti SP, Everett MG (1997) Network analysis of 2-mode data. Soc Networks 19:243-269. https://doi.org/10.1016/S0378 -8733(96)00301-2

Borgatti SP, Mehra A, Brass DJ, Labianca G (2009) Network analysis in the social sciences. Science 323:892-895. https://doi. org/10.1126/science. 1165821

Cohen PJ, Evans LS, Mills M (2012) Social networks supporting governance of coastal ecosystems in Solomon Islands. Conserv Lett 5:376-386. https://doi.org/10.1111/j.1755-263X.2012.00255.x

Dorninger C, Abson DJ, Apetrei CI, Derwort P, Ives CD, Klaniecki K, Lam DPM, Langsenlehner M, Riechers M, Spittler N, von Wehrden H (2020) Leverage points for sustainability transformation: a review on interventions in food and energy systems. Ecol Econ 171:106570. https://doi.org/10.1016/j.ecolecon.2019.10657 0

Fischer J, Riechers M (2019) A leverage points perspective on sustainability. People Nat 1:1-6. https://doi.org/10.1002/pan3.13

Fischer J, Horcea-Milcu AI, Hartel T, Hanspach J, Mikulcak F (2015) The Future of People and Nature in Southern Transylvania. Pensoft

Fischer J, Horcea-Milcu A-I, Lang DJ, Thale-Bombien L, Abson DJ, Apetrei CI, Clarke E, Derwort P, Dorninger C, Duse IA, Freeth R, Jager NW, Klaniecki K, Lam D, Leventon J, Newig J, Peukert D, Riechers M, Schaal T (2019) Balance Brings Beauty: Strategies for a Sustainable Southern Transylvania. Pensoft

Frantzeskaki N, Wittmayer J, Loorbach D (2014) The role of partnerships in 'realising' urban sustainability in Rotterdam's City Ports Area, The Netherlands. J Clean Prod 65:406-417. https:// doi.org/10.1016/j.jclepro.2013.09.023

Freeman LC (1978) Centrality in Social Networks: conceptual Clarification. Soc Networks 1:215-239. https://doi.org/10.1016/03788733(78)90021-7

Garrah J, Frei B, Bennett EM (2019) Bright spots among lakes in the Rideau Valley Watershed, Ontario. Ecol Soc 24:art22. https://doi. org/10.5751/ES-11073-240322

Geels FW (2002) Technological transitions as evolutionary reconfiguration processes: a multi-level perspective and a casestudy. Res Policy 31:1257-1274. https://doi.org/10.1016/S0048 $-7333(02) 00062-8$

Gorissen L, Spira F, Meynaerts E, Valkering P, Frantzeskaki N (2018) Moving towards systemic change? Investigating acceleration dynamics of urban sustainability transitions in the Belgian City of Genk. J Clean Prod 173:171-185. https://doi.org/10.1016/j. jclepro.2016.12.052

Grin J, Rotmans J, Schot J (eds) (2010) Transitions to sustainable development: new directions in the study of long term transformative change. Routledge, New York

Hanspach J, Hartel T, Milcu AI, Mikulcak F, Dorresteijn I, Loos J, von Wehrden $\mathrm{H}$, Kuemmerle T, Abson D, Kovács-Hostyánszki A, Báldi A, Fischer J (2014) A holistic approach to studying socialecological systems and its application to southern Transylvania. Ecol Soc 19:art32. https://doi.org/10.5751/ES-06915-190432

Hauck J, Schmidt J, Werner A (2016) Using social network analysis to identify key stakeholders in agricultural biodiversity governance and related land-use decisions at regional and local level. Ecol Soc 21:art49. https://doi.org/10.5751/ES-08596-210249
Hawken P (2007) Blessed unrest: how the largest social movement in history is restoring grace, justice, and beauty to the World. Penguin Books, London

Hopkins R (ed) (2008) The transition handbook: from oil dependency to local resilience. UIT Cambridge Ltd., Cambridge

Horcea-Milcu AI, Abson DJ, Dorresteijn I, Loos J, Hanspach J, Fischer J (2018) The role of co-evolutionary development and value change debt in navigating transitioning cultural landscapes: the case of Southern Transylvania. J Environ Plan Manag 61:800 817. https://doi.org/10.1080/09640568.2017.1332985

Horcea-Milcu A-I, Martín-López B, Lam DPM, Lang DJ (2020) Research pathways to foster transformation: linking sustainability science and social-ecological systems research. Ecol Soc 25:art13. https://doi.org/10.5751/ES-11332-250113

IPCC (2018) Global warming of $1.5^{\circ} \mathrm{C}$ : An IPCC Special Report on the impacts of global warming of $1.5^{\circ} \mathrm{C}$ above pre-industrial levels and related global greenhouse gas emission pathways, in the context of strengthening the global response to the threat of climate change. In: Masson-Delmotte V, Zhai P, Pörtner H-O, Roberts D, Skea J, Shukla PR, Pirani A, Moufouma-Okia W, Péan C, Pidcock R, Connors S, Matthews JBR, Chen Y, Zhou X, Gomis MI, Lonnoy E, Maycock T, Tignor M, Waterfield $\mathrm{T}$ (eds) In press

Kates RW, Clark WC, Corell R, Hall JM, Jaeger CC, Lowe I, McCarthy JJ, Schellnhuber HJ, Bolin B, Dickson NM, Faucheux S, Gallopin GC, Grübler A, Huntley B, Jäger J, Jodha NS, Kasperson RE, Mabogunje A, Matson P, Mooney H, Moore B, O'Riordan T, Svedin U (2001) Sustainability Science. Science 292:641-642

Köhler J, Geels FW, Kern F, Markard J, Onsongo E, Wieczorek A, Alkemade F, Avelino F, Bergek A, Boons F, Fünfschilling L, Hess D, Holtz G, Hyysalo S, Jenkins K, Kivimaa P, Martiskainen M, McMeekin A, Mühlemeier MS, Nykvist B, Pel B, Raven R, Rohracher H, Sandén B, Schot J, Sovacool B, Turnheim B, Welch D, Wells P (2019) An agenda for sustainability transitions research: state of the art and future directions. Environ Innov Soc Transitions 31:1-32. https://doi.org/10.1016/j.eist.2019.01.004

Komiyama H, Takeuchi K (2006) Sustainability science: building a new discipline. Sustain Sci 1:1-6. https://doi.org/10.1007/s1162 5-006-0007-4

Lam DPM, Horcea-Milcu AI, Fischer J, Peukert D, Lang DJ (2020a) Three principles for co-designing sustainability intervention strategies: experiences from Southern Transylvania. Ambio 49:14511465. https://doi.org/10.1007/s13280-019-01302-x

Lam DPM, Martín-López B, Wiek A, Bennett EM, Frantzeskaki N, Horcea-Milcu AI, Lang DJ (2020b) Scaling the impact of sustainability initiatives: a typology of amplification processes. Urban Transform 2:3. https://doi.org/10.1186/s42854-020-00007-9

Liehr S, Röhrig J, Mehring M, Kluge T (2017) How the social-ecological systems concept can guide transdisciplinary research and implementation: addressing water challenges in Central Northern Namibia. Sustainability 9:1109. https://doi.org/10.3390/su907 1109

Loorbach D, Frantzeskaki N, Avelino F (2017) Sustainability transitions research: transforming science and practice for societal change. Annu Rev Environ Resour 42:599-626. https://doi. org/10.1146/annurev-environ-102014-021340

Loorbach D, Wittmayer J, Avelino F, Von Wirth T, Frantzeskaki N (2020) Transformative innovation and translocal diffusion. https ://doi.org/10.1016/j.eist.2020.01.009

Martín-López B, Felipe-Lucia MR, Bennett EM, Norström A, Peterson G, Plieninger T, Hicks CC, Turkelboom F, García-Llorente M, Jacobs S, Lavorel S, Locatelli B (2019) A novel telecoupling framework to assess social relations across spatial scales for ecosystem services research. J Environ Manage 241:251-263. https ://doi.org/10.1016/j.jenvman.2019.04.029

Meadows DH (1999) Leverage points: places to intervene in a system. The Sustainability Institute, Hartland 
Meadows DH, Meadows DL, Randers J, Behrens WW (1972) The limits to growth. Universe Books, New York

Moore ML, Westley F (2011) Surmountable chasms: networks and social innovation for resilient systems. Ecol Soc 16:art5

Moore M-L, Tjornbo O, Enfors E, Knapp C, Hodbod J, Baggio JA, Norström A, Olsson P, Biggs D (2014) Studying the complexity of change: toward an analytical framework for understanding deliberate social-ecological transformations. Ecol Soc 19:art54. https://doi.org/10.5751/ES-06966-190454

Moore M-L, Riddell D, Vocisano D (2015) Scaling out, scaling up, scaling deep: strategies of non-profits in advancing systemic social innovation. J Corp Citizsh 2015:67-84. https://doi.org/10.9774/ GLEAF.4700.2015.ju.00009

Newman MEJ (2004) Analysis of weighted networks. Phys Rev E 70:056131. https://doi.org/10.1103/PhysRevE.70.056131

Nieto-Romero M, Milcu A, Leventon J, Mikulcak F, Fischer J (2016) The role of scenarios in fostering collective action for sustainable development: lessons from central Romania. Land Use Policy 50:156-168. https://doi.org/10.1016/j.landusepol.2015.09.013

Olsson P, Folke C, Hahn T (2004) Social-ecological transformation for ecosystem management: the development of adaptive co-management of a wetland landscape in Southern Sweden. Ecol Soc 9:2

Olsson P, Gunderson LH, Carpenter SR, Ryan P, Lebel L, Folke C, Holling CS (2006) Shooting the rapids: navigating transitions to adaptive governance of social-ecological systems. Ecol Soc 11:art18

Patterson J, Schulz K, Vervoort J, van der Hel S, Widerberg O, Adler C, Hurlbert M, Anderton K, Sethi M, Barau A (2017) Exploring the governance and politics of transformations towards sustainability. Environ Innov Soc Transitions 24:1-16. https://doi.org/10.1016/j. eist.2016.09.001

Pereira LM, Bennett E, Biggs R, Peterson G, McPhearson T, Norström A, Olsson P, Preiser R, Raudsepp-Hearne C, Vervoort J (2018) Seeds of the future in the present. In: Elmqvist T, Bai X, Frantzeskaki N, Griffith C, Maddox D, McPhearson T, Parnell S, Romero-Lankao P, Simon D, Watkins M (eds) The urban planet: knowledge towards sustainable cities. Cambridge University Press, Cambridge, pp 327-350

Prell C (2011) Social network analysis: history, theory and methodology. SAGE Publications Ltd, London

Prell C, Hubacek K, Reed M (2009) Stakeholder Analysis and social network analysis in natural resource management. Soc Nat Resour 22:501-518. https://doi.org/10.1080/08941920802199202

Rico García-Amado L, Ruiz Pérez M, Iniesta-Arandia I, Dahringer G, Reyes F, Barrasa S (2012) Building ties: social capital network analysis of a forest community in a biosphere reserve in Chiapas, Mexico. Ecol Soc 17:3. https://doi.org/10.5751/ES-04855-170303
Salpeteur M, Calvet-Mir L, Diaz-Reviriego I, Reyes-García V (2017) Networking the environment: social network analysis in environmental management and local ecological knowledge studies. Ecol Soc 22:art41. https://doi.org/10.5751/ES-08790-220141

Schlüter M, Haider LJ, Lade SJ, Lindkvist E, Martin R, Orach K, Wijermans N, Folke C (2019) Capturing emergent phenomena in social-ecological systems: an analytical framework. Ecol Soc 24:art11. https://doi.org/10.5751/ES-11012-240311

Scoones I, Stirling A, Abrol D, Atela J, Charli-Joseph L, Eakin H, Ely A, Olsson P, Pereira L, Priya R, van Zwanenberg P, Yang L (2020) Transformations to sustainability: combining structural, systemic and enabling approaches. Curr Opin Environ Sustain 42:65-75. https://doi.org/10.1016/j.cosust.2019.12.004

Smith M, A. C, Milic-Frayling N, Shneiderman B, Mendes Rodrigues E, Leskovec J, Dunne C (2010) NodeXL: a free and open network overview, discovery and exploration add-in for Excel 2007/2010/2013/2016, from the Social Media Research Foundation: https://www.smrfoundation.org

Smith A, Raven R (2012) What is protective space? Reconsidering niches in transitions to sustainability. Res Policy 41:1025-1036. https://doi.org/10.1016/j.respol.2011.12.012

Stirling A (2015) Emancipating Transformations: From controlling 'the transition' to culturing plural radical progress. In: Scoones I, Leach M, Newell P (eds) Pathways to sustainability: the politics of green transformations. Routledge, Oxon, New York, pp 54-67

Wasserman S, Faust K (1994) Social network analysis: methods and applications. Cambridge University Press, New York

Westley F, Zimmerman B, Patton M (eds) (2006) Getting to maybe: how the world is changed. Vintage Canada, Toronto

Westley F, Olsson P, Folke C, Homer-Dixon T, Vredenburg H, Loorbach D, Thompson J, Nilsson M, Lambin E, Sendzimir J, Banerjee B, Galaz V, van der Leeuw S (2011) Tipping toward sustainability: emerging pathways of transformation. Ambio 40:762-780. https://doi.org/10.1007/s13280-011-0186-9

Westley F, McGowan K, Tjörnbo O (2017) The evolution of social innovation. Edward Elgar Publishing, Cheltenham, UK, Northampton

Wiek A, Lang DJ (2016) Transformational sustainability research methodology. In: Heinrichs H, Martens P, Michelsen G, Wiek A (eds) Sustainability Science. Springer, Dordrecht, pp 31-41

Publisher's Note Springer Nature remains neutral with regard to jurisdictional claims in published maps and institutional affiliations. 